\title{
BMJ Open Examining the associations between HIV-related stigma and health outcomes in people living with HIV/AIDS: a series of meta-analyses
}

\author{
Sergio Rueda, ${ }^{1,2,3,4}$ Sanjana Mitra, ${ }^{5}$ Shiyi Chen, ${ }^{5}$ David Gogolishvili, ${ }^{5}$ \\ Jason Globerman, ${ }^{5}$ Lori Chambers, ${ }^{6}$ Mike Wilson, ${ }^{7,8}$ Carmen H Logie, ${ }^{9}$ \\ Qiyun Shi, ${ }^{5}$ Sara Morassaei, ${ }^{4}$ Sean B Rourke $2,5,10$
}

To cite: Rueda S, Mitra S, Chen $\mathrm{S}$, et al. Examining the associations between HIVrelated stigma and health outcomes in people living with HIV/AIDS: a series of meta-analyses. BMJ Open 2016;6: 011453.

doi:10.1136/bmjopen-2016011453

- Prepublication history and additional material is available. To view please visit the journal (http://dx.doi.org/ 10.1136/bmjopen-2016011453).

Received 10 February 2016 Revised 18 May 2016 Accepted 9 June 2016

CrossMark

For numbered affiliations see end of article.

Correspondence to Dr Sergio Rueda; ruedagento@gmail.com

\section{ABSTRACT}

Objective: To conduct a systematic review and series of meta-analyses on the association between HIVrelated stigma and health among people living with HIV.

Data sources: A structured search was conducted on 6 electronic databases for journal articles reporting associations between HIV-related stigma and healthrelated outcomes published between 1996 and 2013.

Study eligibility criteria: Controlled studies, cohort studies, case-control studies and cross-sectional studies in people living with HIV were considered for inclusion.

Outcome measures: Mental health (depressive symptoms, emotional and mental distress, anxiety), quality of life, physical health, social support, adherence to antiretroviral therapy, access to and usage of health/ social services and risk behaviours.

Results: 64 studies were included in our metaanalyses. We found significant associations between HIV-related stigma and higher rates of depression, lower social support and lower levels of adherence to antiretroviral medications and access to and usage of health and social services. Weaker relationships were observed between HIV-related stigma and anxiety, quality of life, physical health, emotional and mental distress and sexual risk practices. While risk of bias assessments revealed overall good quality related to how HIV stigma and health outcomes were measured on the included studies, high risk of bias among individual studies was observed in terms of appropriate control for potential confounders. Additional research should focus on elucidating the mechanisms behind the negative relationship between stigma and health to better inform interventions to reduce the impact of stigma on the health and well-being of people with HIV.

Conclusions: This systematic review and series of meta-analyses support the notion that HIV-related stigma has a detrimental impact on a variety of healthrelated outcomes in people with HIV. This review can inform the development of multifaceted, intersectoral interventions to reduce the impact of HIV-related stigma on the health and well-being of people living with HIV.

\section{Strengths and limitations of this study}

- This systematic review and series of meta-analyses examined a wide range of associations between stigma and health, supporting the notion that HIV-related stigma has a detrimental impact on a variety of health-related outcomes in people living with HIV.

- It performed a comprehensive search of the literature, used independent reviewers and a consensus approach to select and extract data from relevant papers, performed a detailed quality appraisal of the included studies, used appropriate methods to combine the findings of studies and assessed the likelihood of publication bias where appropriate.

- Substantial heterogeneity was observed for some outcomes, and a small number of studies were available to be pooled in meta-analyses for other outcomes.

- While risk of bias assessments revealed overall good quality for some domains, the majority of studies only presented bivariate associations, potentially obscuring the association between HIV stigma and health outcomes in this review.

- Future reviews should perform a systematic evaluation of the mechanisms involved in the relationship between HIV-related stigma and health, the role a variety of factors play in reducing the negative effects of stigma on health and examine the intersection between stigma and other forms of social exclusion.

\section{BACKGROUND}

According to the Global Network of People Living with HIV/AIDS, one of the biggest challenges facing people living with HIV today is stigma and discrimination. ${ }^{1}$ HIV-related stigma in this context has been defined as discounting, discrediting and discriminating against people perceived to have HIV. $^{2} 3$ Overall, stigma continues to be 
prevalent in the context of HIV, whether measured in terms of the attitudes of those who are not infected ${ }^{4}$ or in terms of the experiences of those living with HIV. ${ }^{5} 6$ The mechanisms through which stigma may be experienced by those living with HIV include enacted stigma, anticipated stigma and internalised stigma. ${ }^{5}$ Enacted stigma refers to discrimination experienced by people with HIV, and may include acts of violence and marginalisation. Anticipated stigma is awareness of negative social perceptions towards HIV and the expectation that a person living with HIV will experience prejudice and discrimination in the future. Internalised stigma refers to the endorsement of negative beliefs, views and feelings of oneself as it relates to one's HIV-positive status. ${ }^{5}$ In other words, for those living with HIV, the knowledge that their HIV status is a socially devalued aspect of themselves may be experienced in a variety of ways, ranging from actually being the object of prejudice and discrimination from others to holding negative beliefs and feelings about themselves. ${ }^{7}$ Stigma may arise from misconceptions about HIV transmission and from judgmental attitudes towards those social groups that are disproportionately affected by HIV, including men who have sex with men (MSM), Aboriginal people, people from countries where HIV is endemic, ethnic minorities, and injection drug users. ${ }^{8-10}$

Stigma and discrimination negatively affect people living with HIV. A recent review of the qualitative evidence showed that HIV-related stigma is a broad and global social phenomenon that manifests within multiple social domains, including healthcare environments. ${ }^{11}$ Studies have reported on HIV discrimination in healthcare environments including denial of care or treatment, HIV testing without consent, confidentiality breaches, negative attitudes and humiliating practices by healthcare workers. ${ }^{12-14}$ Models linking the experience to negative outcomes have been developed and tested, especially in the areas of racial discrimination, physical and mental health ${ }^{15-20}$ and substance use. ${ }^{21}{ }^{22}$ HIV-related stigma is associated with poorer mental health outcomes, including emotional distress, ${ }^{23-26}$ shame, ${ }^{27}$ depression, ${ }^{6}{ }^{28-30}$ reduced self-esteem, ${ }^{31}$ reduced psychological functioning, ${ }^{25}$ poorer psychological adjustment, ${ }^{32}$ negative affect, ${ }^{33}$ anxiety, ${ }^{34-36}$ suicidal ideation, ${ }^{3738}$ life satisfaction, ${ }^{39}$ quality of life $e^{4041}$ and stress associated with disclosure. ${ }^{23}$ Other studies have identified the impact of stigma on a person's selfvaluation or mental outlook once his or her status is known. ${ }^{42}{ }^{43}$ Stigma has also been linked with secondary health-related factors including seeking healthcare and adherence to antiretroviral therapy ${ }^{44-47}$ A meta-analysis by Logie and Gadalla (2009) demonstrated that high levels of stigma were consistently and significantly associated with low social support and poorer physical and mental health outcomes in North American contexts. ${ }^{48}$

Given the growing body of research that documents the relationship between stigma and health among people living with HIV, and the limited number of studies that summarise and integrate this body of work, the current systematic review of the quantitative evidence complements our recent review of qualitative research, ${ }^{11}$ and further builds on the work of Logie and Gadalla (2009) by including a large number of recent studies from a wider scope of contexts and outcomes, and organising the health outcomes in a more clinically meaningful way. This includes mental health (depressive symptoms, emotional and mental distress, anxiety), quality of life and physical health outcomes. In addition, the present review uniquely examines the association between HIV-related stigma and additional intermediate health-related outcomes such as adherence to antiretroviral medications, social support, access and usage of health and social services, and sexual risk behaviours. This knowledge base informs the need to further develop and evaluate interventions addressing HIVrelated stigma for people living with HIV/AIDS.

\section{METHODS}

\section{Search strategy}

A systematic search of six databases (Medline, EMBASE, PsycInfo, CINAHL Sociological Abstracts and WHOLIS) for journal articles published between January 1996 (with the advent of combination antiretroviral therapy) and September 2013 was conducted. MeSH and/or keyword terms related to HIV/AIDS and stigma were adapted for each specific database (see online supplementary file 1 for search strategies). The search strategy also included literature recommended by content experts, and a citation search of literature included at the stage of full-text article review. The study protocol was peer-reviewed and was funded by the Canadian Institutes of Health Research.

\section{Inclusion/exclusion criteria}

All controlled studies (ie, randomised controlled trials and quasiexperimental studies), cohort studies, casecontrol studies and cross-sectional studies that measured the association between HIV-related stigma and health-related outcomes in people living with HIV were considered for inclusion. Studies were included in this review if they: (1) were published in English, French or Spanish after 1996; (2) included people living with HIV; (3) reported HIV-related stigma as a predictor of health outcomes, such as mental and physical health, access to and usage of care, adherence to antiretroviral therapy, social support, sexual risk behaviours; (4) reported any one of the following statistics: correlation coefficient and sample sizes, ORs and $95 \%$ confidence limits, regression coefficients and SE or $95 \%$ confidence limits, or other statistics that could be converted into a standardised effect size.

Studies were excluded if: (1) no primary data were reported; (2) full-text articles were not available after exhaustive searches to locate them; (3) there were insufficient or missing data (after contacting authors); 
(4) groups of studies had considerable heterogeneity (variation in outcomes between studies). Studies with rare outcomes such as food insecurity, the positive legacy of trauma, sexual compulsivity and affect balance were excluded as these outcomes were unique to one study and therefore not meta-analysable.

Although the importance of understanding the health impact of HIV-related stigma on communities that have been disproportionally impacted by HIV was recognised (eg, MSM, women, people who use drugs, Aboriginal people, racialised communities, immigrants and refugees), the focus of our analysis was on people living with HIV irrespective of cultural identity, sexual orientation, or sexual risk behaviours. This review was also restricted to HIV stigma on health outcomes regardless of the intersecting effects of other types of stigma related to social positioning.

\section{Screening and data extraction}

The screening phase was conducted on DistillerSR, an online application specifically designed for knowledge syntheses (DistillerSR [program]. Ottawa, Canada, 2014). A customised checklist reflecting the selection criteria facilitated the selection process. The form was pilot tested using 75 citations each at the title-and-abstract, and full-text article review stages to determine the reliability of the inclusion criteria. Data extracted included author name, year of publication, study jurisdiction (country), study design, sample size, stigma measure, outcome measure, statistical analysis (univariate or multivariate) and key statistical data.

The inclusion process was conducted in three stages: The first stage was title-and-abstract review, where references were reviewed to determine clear exclusions. The second stage was full-text article review, where the paper was retrieved and reviewed to determine general applicability to the review aims. The third stage was methodology review, where the full-text article was reviewed based on inclusion criteria. All three stages were completed by two reviewers independently. Any disagreements between reviewers were resolved by consensus. To determine inter-rater reliability, $\kappa$-statistic was used and found to be 0.65 , suggesting substantial agreement.

\section{Quality appraisal}

The quality appraisal tool was adapted from the Newcastle-Ottawa Scale ${ }^{49}$ to have a single risk of bias assessment for all study designs. Each study was awarded one rating (good, fair or poor) for each of the three domains: exposure, outcome and comparability. Quality in the exposure domain was considered 'good' if HIV stigma was measured using validated tools; 'fair' if HIV stigma was measured using tools developed by the authors for that particular study; and 'poor' if the authors made no attempts to properly measure stigma. Quality in the outcome domain was considered 'good' if the authors used an objective measure (eg, record linkage, diagnosis made by the clinician, laboratory findings) or used validated self-report measures; 'fair' if the authors used a self-report measure, but limited information regarding reliability and validity was referenced or provided in the paper; and 'poor' if the definition of the outcome was vague, unclear or the measurement of the outcome was poor (eg, questionnaire developed by the authors for that particular study). Quality in the comparability domain was 'good' if studies controlled for at least one demographic or social economic status variable confounder (eg, age, sex, income), and at least one behavioural health indicator; 'fair' if studies controlled for at least one potential demographic or social economic status variable confounder (eg, age, sex, income); and 'poor' if there was lack of adjustment for potential confounders (eg, bivariate analysis). Quality assessments for included studies were completed by two independent reviewers.

\section{Statistical methods}

\section{Summary effect size and type of analyses}

The effect size statistic was defined as the association between HIV-related stigma and health outcomes. Statistical data such as ORs (with 95\% CIs), correlations (with sample sizes) and regression coefficients (with SEs or $95 \%$ CIs) were recorded. Summary effect sizes were calculated with inverse variance weighting and presented as univariate analyses and OR, or regression coefficients for the multivariate analyses. No additional data are available to share.

Meta-analysis was conducted separately for studies that reported univariate and multivariate results. If both univariate and multivariate results were provided, multivariate statistics for the meta-analyses were used. For each meta-analysis, we created forest plots to show the magnitude of effects. We used Comprehensive Meta-Analysis-V.2 to perform the statistical analyses (Comprehensive Meta-analysis [program]. 2 version. Englewood New, Jersey: Biostat. 2005).

HIV-related stigma was measured in different studies using a variety of instruments. For studies that reported more than one type of HIV-related stigma (eg, internalised stigma, personalised stigma, self-stigma, enacted stigma), the finding with the highest strength of the association with the outcome was selected. Also, the statistics in table 1 have been adjusted for effect direction. For example, some studies measured the association between HIV-related stigma and delay to healthcare, providing a positive correlation to describe this relationship. In these cases, the direction of this correlation was adjusted to reflect the negative relationship between HIV-related stigma and access to healthcare, as a delay in healthcare may be considered detrimental to health.

\section{Model selection and publication bias}

Meta-analyses were performed based on a random effects model because the definitions and measurement scales for the predictor and outcome variables varied across studies, and true effect sizes varied from study to study. 


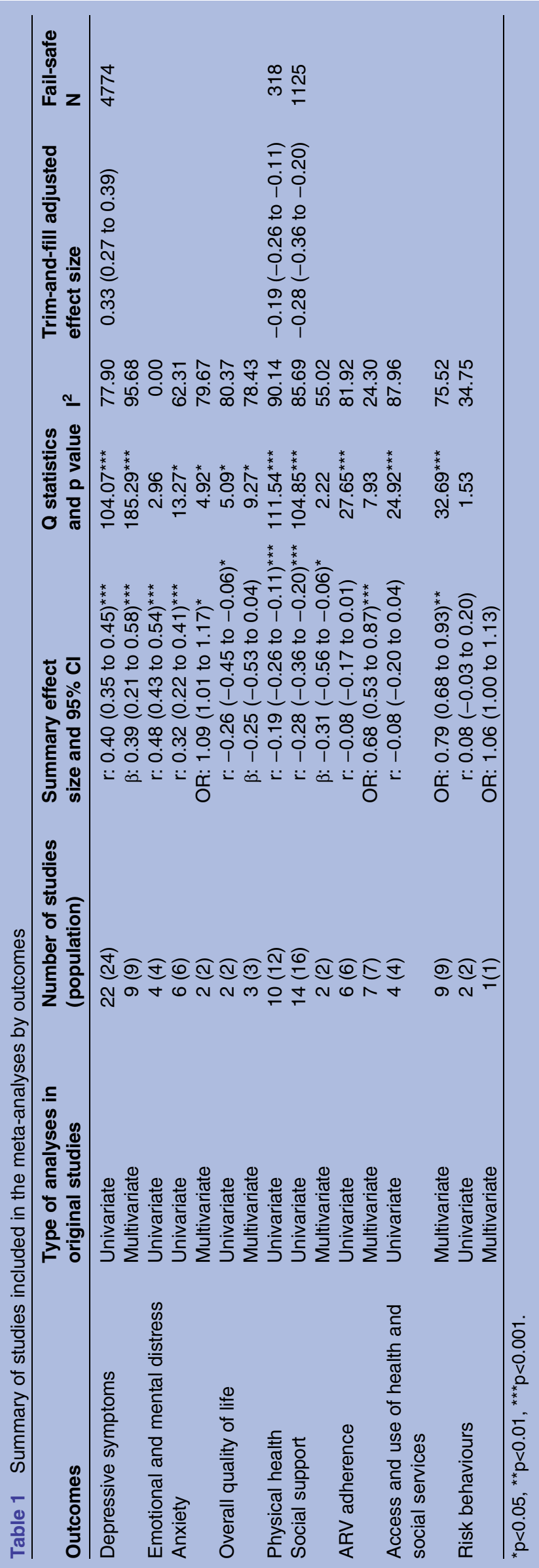

With random effects models, two sources of uncertainty are taken into account: within-study sampling error and between-study variance. Heterogeneity in true effect sizes between studies was indicated by large Cochran's $Q$ statistics with small $\mathrm{p}$ values, and large $\mathrm{I}^{2}$ statistics. ${ }^{51}$ Publication bias was assessed for meta-analyses that included more than 10 studies for one particular outcome variable. Funnel plots, trim-and-fill analysis and Rosenthal's fail-safe number were used to assess publication bias. ${ }^{52} 53$

\section{RESULTS}

Identification, screening and eligibility

Figure 1 illustrates the study inclusion/exclusion process. A total of 14010 titles and abstracts were retrieved through electronic databases, and 224 studies identified through experts and reference checking. After removing duplicates, 9284 potentially eligible records remained. After further screening, eligibility assessment was performed with 1067 full-text articles; these were checked against the exclusion criteria and 120 studies remained for inclusion. After removing studies due to heterogeneity (eg, rare outcomes), missing data and duplicate data, 64 studies were included in the final series of meta-analyses.

\section{Description of included studies}

Sixty-four studies were included in our meta-analysis (see online supplementary file 2 for the characteristics of the included studies). The total sample size was 20 012. Forty-two of these studies were conducted in the USA, three in India, two each in Canada, Zambia and South Africa, and one each in the Netherlands, Vietnam, Congo, China, Lebanon, Hong Kong, France, Ethiopia, Thailand and Honduras. One study included data from multiple countries. Among these 64 studies, one was a randomised controlled trial, nine used longitudinal study design, one was a case-control study, and 53 had cross-sectional study designs. Separate metaanalyses were performed for different health outcomes and different statistical methods (univariate and multivariate study results). Some of these studies reported more than one health outcome, so the same study may have contributed to different meta-analyses.

\section{Measures of HIV-related stigma and health-related outcomes}

The most commonly used HIV-related stigma measures were the Berger Stigma Scale, ${ }^{28}$ HIV Stigma Measure, ${ }^{54}$ Internalized AIDS-Related Stigma Scale,${ }^{55}$ and Demi-HIV Stigma Scale (A Demi, R Bakeman, R Sowell, et al. Psychometric evaluation of the Demi HIV Stigma Scale. Unpublished manuscript. 2001). For mental health outcomes, studies reported on the relationship between HIV-related stigma and depression, emotional and mental distress, and anxiety: (1) depression was commonly measured using the Center for Epidemiologic Studies Depression Scale $^{56}$ and the Brief Symptom 


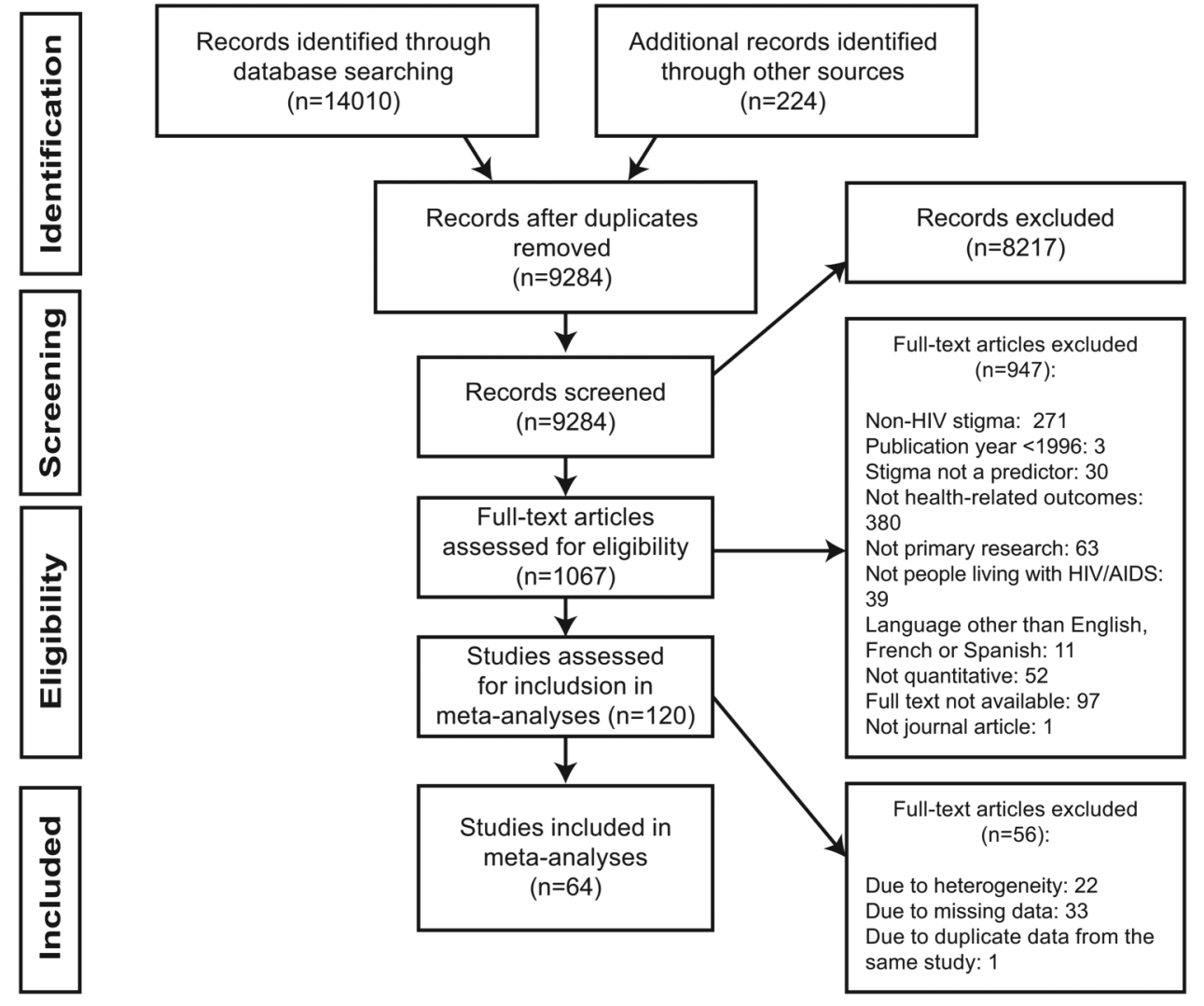

Figure 1 Flow diagram of study included in meta-analysis.

Inventory (BSI) depression subscale $;^{57}$ (2) emotional and mental distress reflects the range of emotional and mental symptoms and conditions experienced by people living with HIV (measured by the SF-12 mental health survey $^{58}$ or self-reported emotional and distress levels); (c) anxiety was measured using the BSI anxiety subscale $^{57}$ State anxiety $^{59}$ and the Symptom Check List-90-R. ${ }^{60}$ Overall quality of life was measured using WHO's Quality of Life-HIV BREF, ${ }^{61}$ HIV/AIDS Targeted Quality Life instrument ${ }^{62}$ and others. Physical health described HIV symptoms and physical well-being of people living with HIV. Instruments included the SF-12 physical health ${ }^{58}$ and Medical Outcomes Study HIV Health Survey. ${ }^{63}$ Social Support was most commonly measured by the Social Support Questionnaire ${ }^{64}$ and the Medical Outcomes Study-Social Support Subscale. ${ }^{65}$ Adherence to antiretroviral therapy was measured by selfreport or the UCSF Adherence Questionnaire. ${ }^{66}$ Access and use of health and social services measured the degree that people living with HIV have access to and use healthcare units, clinics and social services. Measurements include retention in care and seeking medical care. Sexual risk behaviours include unprotected sex. Measures included the NIMH Multisite Cooperative Agreement sexual risk assessment. ${ }^{67}$

\section{Quality appraisal}

The risk of bias graph presents the risk of bias in each domain (exposure, outcome and comparability) across all included studies (figure 2 ). The risk of bias summary (figure 3) presents the assessment of the quality in each domain for each study separately. Exposure. Our quality appraisal found that $46(72 \%)$ studies have good quality in the exposure domain. Eleven $(17 \%)$ and seven $(11 \%)$ studies have fair and poor quality in the exposure domain respectively. A majority of the studies $(\mathrm{k}=46)$ had good exposure quality as they used validated tools to measure exposure. Outcome: A majority of studies $(\mathrm{k}=57)$ used objective measures of quality in the outcome domain such as validated questionnaires that have been previously published. Fifty-seven (89\%) studies were assessed as having good quality in the outcome domain. Three $(4 \%)$ have fair quality in the outcome domain and four $(7 \%)$ have poor quality in the outcome domain. Comparability: Moreover, eight (12\%) studies have good quality in the comparability domain, 18 (29\%) have fair quality in the

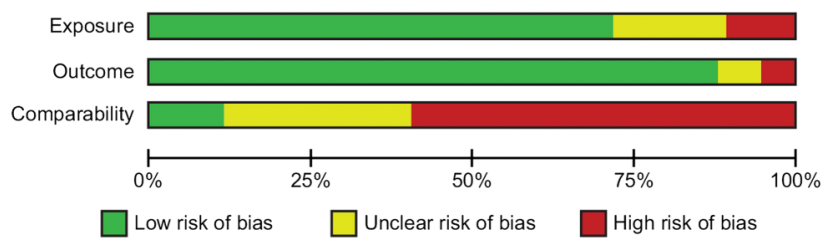

Figure 2 Risk of bias graph: review authors' judgements about each risk of bias item presented as percentages across all included studies. 
Figure 3 Risk of bias summary: review authors' judgements about each risk of bias item for each included study.

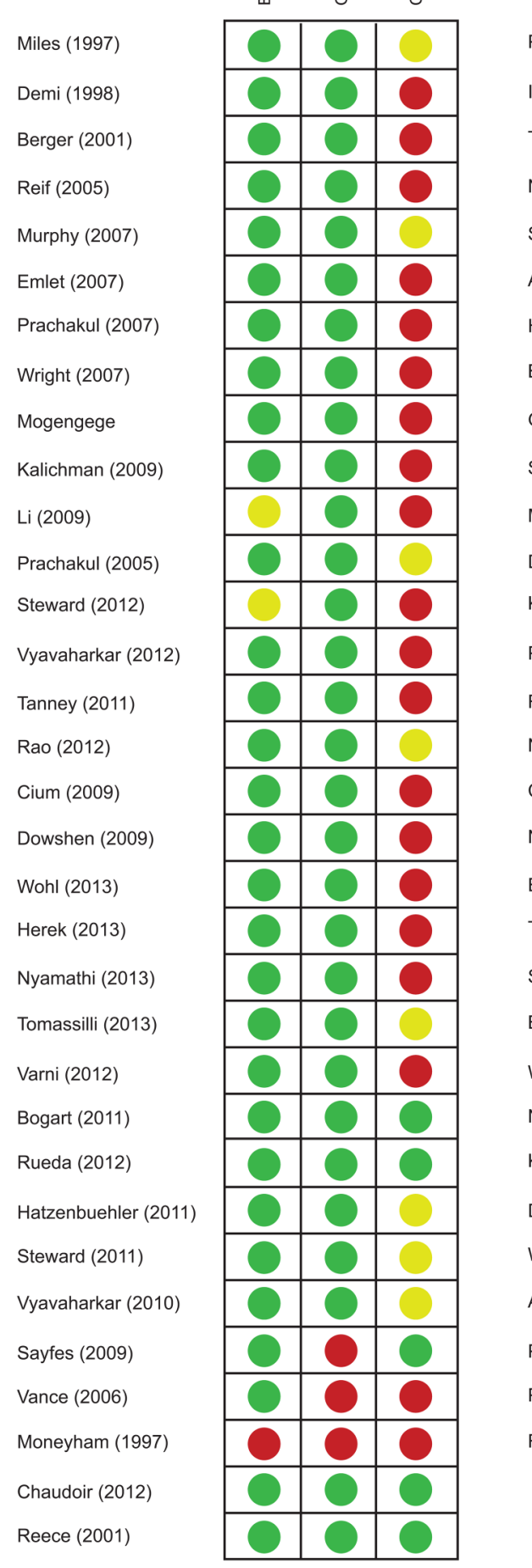

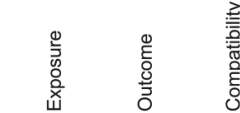

Pappin (2012)

Ivanova (2012)

Tam (2012)

Newman (2012)

Slater (2013)

Abboud (2010)

Heckman (2002)

Bozarth (1998)

Grov (2010)

Sumari-de Boer (2012)

Mak (2007)

Dilorio (2009)

Keeney (2008)

Peretti-Watel (2006)

Rintamaki (2006)

Nachega (2004)

Carlucci (2008)

Nozaki (2011)

Earnshaw (2013)

Traeger (2012)

Sayles (2008)

Brennan (2007)

Wingood (2007)

Naar-King (2007)

Kinsler (2007)

Dietz (2010)

Wohl (2011)

Abaynew (2011)

Paz- Bailey (2012)

Peltzer (2011)

Rao (2012)

Low risk of bias
Unclear risk of bias

High risk of bias comparability domain and $37(58 \%)$ have poor quality in the comparability domain. Few studies $(\mathrm{k}=19)$ controlled for at least one demographic variable and social-economic status variable, and a majority $(\mathrm{k}=37)$ did not control for any confounder at all. Seven longitudinal studies were also assessed for follow-up quality; however, this result was not included in the quality appraisal graph.

\section{Effect sizes and heterogeneity}

For each meta-analysis, table 1 reports the summary effect size and $95 \%$ CI, Q test of homogeneity, the heterogeneity of between-study variance (measured by $\mathrm{I}^{2}$ statistics), and publication bias assessments including the calculated 'trim-and-fill' statistics and fail-safe N. For $\mathrm{I}^{2}$ statistics, $25 \%, 50 \%$ and $75 \%$ represents low, medium and high heterogeneity, respectively. 
Mental health: depressive symptoms

Meta-analysis of 22 articles (24 studies, figure 4) that reported univariate results showed a moderate correlation between HIV-related stigma and depressive symptoms. High heterogeneity was observed for univariate analysis. The eight studies that controlled for potential confounders (multivariate analysis) found that people living with HIV who experienced HIV-related stigma were at a greater risk of higher depressive symptoms. High heterogeneity was observed for multivariate analysis.

\section{Mental health: emotional and mental distress}

Meta-analysis on four studies (figure 5) that reported univariate results found a moderate correlation between HIV-related stigma and increased emotional and mental distress. Although there was no evidence of heterogeneity, the random effect model was still used to be consistent with the statistical analyses adopted throughout this study. ${ }^{51}$
Mental health: anxiety

Meta-analysis on six studies (figure 6) that reported univariate results showed a moderate correlation between HIV-related stigma and heightened anxiety. Medium heterogeneity was observed for univariate analysis. The two studies that controlled for potential confounders found that people who experienced HIV-related stigma were 1.09 times more likely to experience anxiety. High heterogeneity was observed for multivariate analysis.

\section{Overall quality of life}

Meta-analysis on two studies (figure 7) that reported univariate results showed a weak correlation between HIV-related stigma and lower overall quality of life. The three studies that controlled for potential confounders found that people who experienced HIV-related stigma were at higher risk of worse overall quality of life, but the results were not statistically significant. High heterogeneity was observed for both univariate and multivariate analyses.

Univariate Results
Miles (1997)
Demi (1998)
Berger (2001)
Reece (2001)
Relf (2005)
Emlet (2007)
Prachakul (2007)
Wright (2007)
Mogengage (2008)
Kalichman (Swaziland 2009)
Kalichman (Atlanta 2009)
Kalichman (Cape Town 2009)
Li (2009)
Steward (2012)
Vyavahakar (2012)
Tanney (2011)
Clum (2009)
Dowshen (2009)
Herek (2013)
Nyamanthi (2013)
Tomassilli (2013)
Wohl (2013)
Varni (2012)
Bozarth (1998)
Summary Measure

\begin{tabular}{cccc} 
& \multicolumn{3}{c}{ Statistics for Each Study } \\
Correlation & Lower limit & Upper limit & Z-Value \\
0.500 & 0.268 & 0.677 & 3.923 \\
0.520 & 0.415 & 0.611 & 8.372 \\
0.630 & 0.559 & 0.692 & 13.159 \\
0.520 & 0.383 & 0.634 & 6.546 \\
0.280 & 0.074 & 0.463 & 2.637 \\
0.630 & 0.313 & 0.821 & 3.478 \\
0.460 & 0.120 & 0.704 & 2.584 \\
0.350 & 0.114 & 0.549 & 4.219 \\
0.500 & 0.286 & 0.667 & 10.568 \\
0.310 & 0.255 & 0.363 & 5.880 \\
0.380 & 0.261 & 0.488 & 9.035 \\
0.270 & 0.213 & 0.325 & 8.526 \\
0.400 & 0.315 & 0.479 & 11.665 \\
0.360 & 0.304 & 0.414 & 5.725 \\
0.280 & 0.187 & 0.368 & 6.388 \\
0.440 & 0.316 & 0.549 & 3.900 \\
0.314 & 0.160 & 0.453 & 2.325 \\
0.356 & 0.058 & 0.595 & 5.461 \\
0.374 & 0.247 & 0.489 & 0.242 \\
0.030 & -0.210 & 0.267 & 5.461 \\
0.350 & 0.105 & 0.555 & 2.759 \\
0.470 & 0.301 & 0.610 & 5.024 \\
0.340 & 0.211 & 0.457 & 4.970 \\
0.758 & 0.565 & 0.873 & 5.520 \\
0.403 & 0.351 & 0.453 & 13.629
\end{tabular}

$\underline{\text { Multivariate Results }}$

Prachakul (2005)

Murphy (2007)

Bogart (2011)

Rueda (2011)

Hatzenbuehler (2011)

Rao (2012)

Steward (2011)

Vyavaharkar (2010)

Summary Measure

$\begin{array}{ccc}\text { Correlation } & \text { Lower limit } & \text { Upper limit } \\ 0.440 & 0.256 & 0.624 \\ 0.361 & 0.208 & 0.514 \\ 0.000 & -0.098 & 0.098 \\ 0.130 & 0.065 & 0.195 \\ 0.160 & 0.101 & 0.219 \\ 0.670 & 0.572 & 0.768 \\ 10.985 & 7.196 & 14.774 \\ 0.220 & 0.122 & 0.318 \\ 0.301 & 0.127 & 0.476\end{array}$

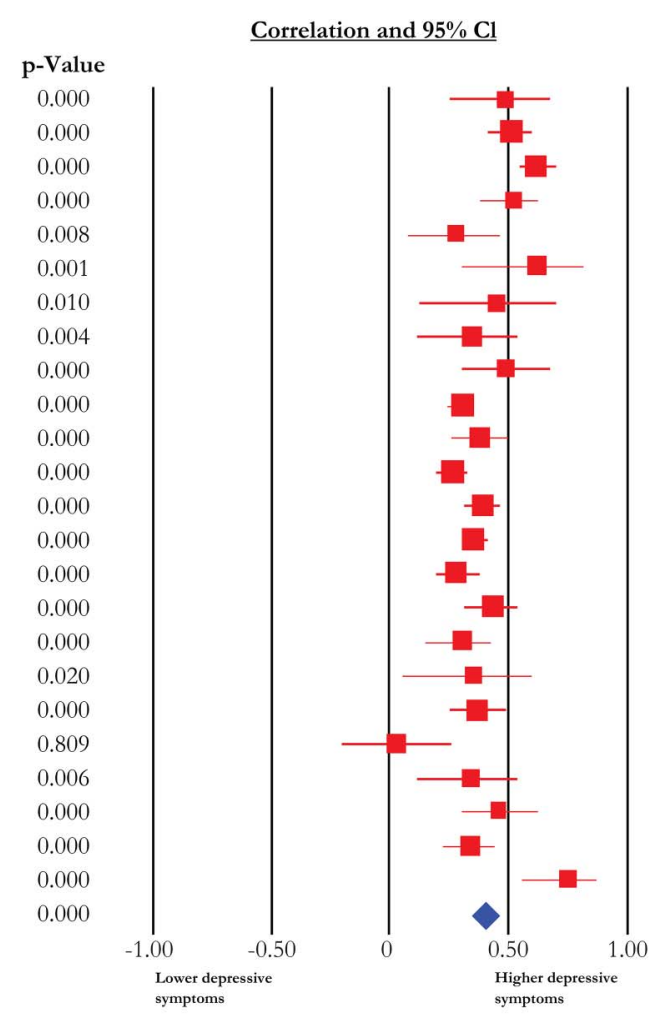

Z-Value

4.681

0.000

3.920

5.333

13.400

5.682

4.400

3.381

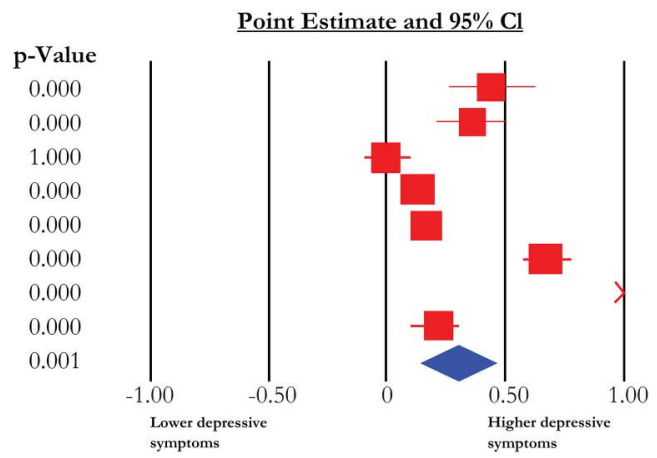

Figure 4 Stigma is associated with higher depressive symptoms (univariate and multivariate results). 
Univariate Results

Sayles (2008)

Vance (2006)

Demi (1998)

Moneyham (1997)

Summary Measure
Statistics for Each Study

$\begin{array}{cccc}\text { Correlation } & \text { Lower limit } & \text { Upper limit } & \text { Z-Value } \\ 0.500 & 0.389 & 0.597 & 7.749 \\ 0.320 & 0.046 & 0.549 & 2.274 \\ 0.530 & 0.426 & 0.620 & 8.572 \\ 0.460 & 0.359 & 0.550 & 8.034 \\ 0.484 & 0.426 & 0.538 & 14.152\end{array}$

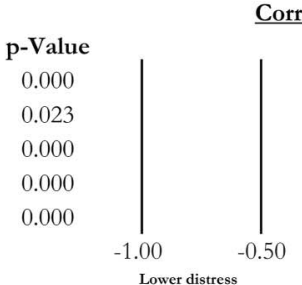

Correlation and $95 \% \mathrm{Cl}$

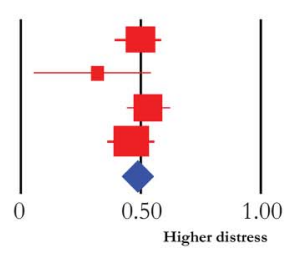

Figure 5 Stigma is associated with higher emotional and mental distress (univariate results).

Univariate Results

Wright (2007)

Reece (2001)

Herek (2013)

Vami (2012)

Hatzenbuehler (2011)

Tomassilli (2013)

Summary Measure

Multivariate Results

Pappin (2012)

Ivanova (2012)

Summary Measure
Statistics for Each Study

Correlation
0.240
0.480
0.367
0.320
0.170
0.320
0.317

Z-Value

0.337

0.239

0.190

0.060

0.072

0.215

0.459

0.602

0.482

0.439

0.276

0.531

0.413

1.072
1.040
1.018

1.072
1.040
1.018

1.212
1.080
1.172

4.177

6.052

2.469

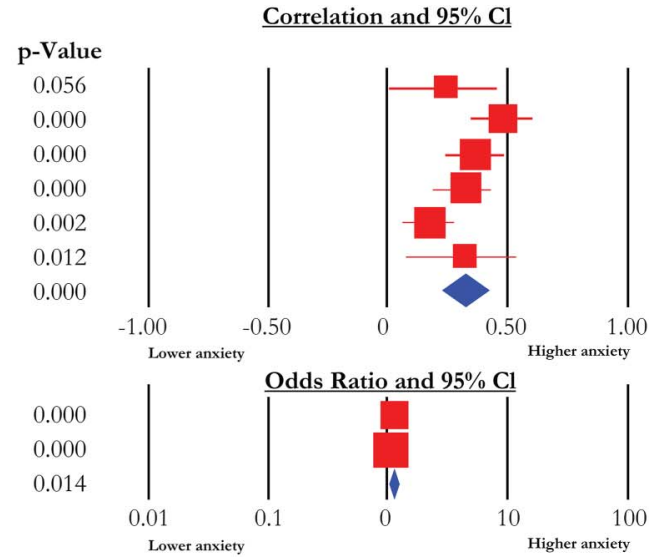

Figure 6 Stigma is associated with higher anxiety symptoms (univariate and multivariate results).
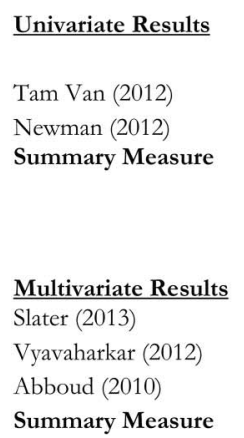

\begin{tabular}{cccc} 
& \multicolumn{3}{c}{ Statistics for Each Study } \\
Correlation & Lower limit & Upper limit & Z-Value \\
-0.360 & -0.468 & -0.241 & -5.653 \\
-0.160 & -0.284 & -0.027 & -2.361 \\
-0.263 & -0.447 & -0.058 & -2.503
\end{tabular}

$-0.210$

$-0.260$

$-21.510$

$-0.245$

-0.367
-0.378
-35.387
-0.526

$-0.367$

$-35.387$

$-0.526$

$$
\begin{aligned}
& -0.053 \\
& -0.142 \\
& -7.633
\end{aligned}
$$

0.037
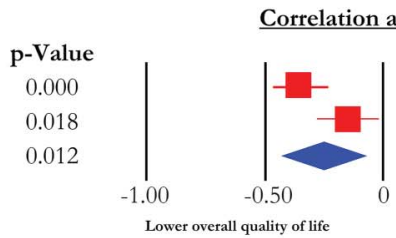

-2.625
-4.333
-3.038
-1.702

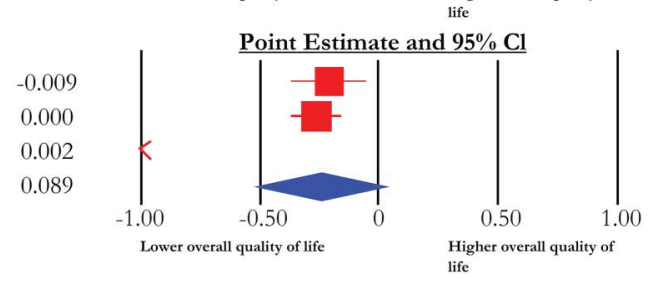

Figure 7 Stigma is associated with lower quality of life (univariate and multivariate results).

\section{Physical health}

A weak correlation was found between HIV-related stigma and greater number of physical symptoms (figure 8). Meta-analysis indicated that people who experienced HIV-related stigma were at a greater risk of poorer physical health. High heterogeneity was observed.

\section{Social support}

For meta-analysis based on univariate results (figure 9), a moderate correlation was found between HIV stigma and lower level of social support. High heterogeneity was observed for this analysis. The two studies that controlled for potential confounders gave the summary point estimate of -0.31 with $95 \%$ CI $(-0.56$ to -0.06$)$. There was no conclusive evidence of heterogeneity for the multivariate analysis.

\section{Adherence to antiretroviral therapy}

Meta-analysis based on univariate results (figure 10) showed a weak correlation between HIV-related stigma and poor adherence to treatment across five studies. However, this correlation was not statistically significant. High heterogeneity was found among the studies. In addition, the seven studies that controlled for potential confounders found that people who experienced HIV-related stigma were $32 \%$ less likely to adhere to antiretroviral therapy. There was no conclusive evidence of heterogeneity.

\section{Access to and usage of health and social services}

Meta-analysis based on univariate results (figure 11) showed a weak correlation between HIV stigma and lower access and usage of services across four studies, although this association was not statistically significant. The nine studies that controlled for potential 
Univariate Results

Miles (1997)

Bozarth (1998)

Demi (1998)

Reece (2001)

Heckman (2002)

Sayles (2008)

Kalichman Cape Town (2009)

Kalichman Swaziland (2009)

Kalichman Atlanta (2009)

Grov (2010)

Nyamathi (2013)

Sumaride Boer (2012)

Summary measure
Statistics for Each Study

$\begin{array}{cccc}\text { Correlation } & \text { Lower limit } & \text { Upper limit } & \text { Z-Value } \\ -0.390 & -0.596 & -0.136 & -2.941 \\ -0.510 & -0.703 & -0.248 & -3.559 \\ -0.290 & -0.408 & -0.162 & -4.337 \\ -0.450 & -0.577 & -0.302 & -5.505 \\ -0.220 & -0.416 & -0.005 & -2.000 \\ -0.140 & -0.273 & -0.002 & -1.988 \\ -0.050 & -0.110 & 0.010 & -1.633 \\ -0.180 & -0.237 & -0.122 & -6.000 \\ -0.120 & -0.249 & 0.013 & -1.772 \\ -0.090 & -0.154 & -0.025 & -2.724 \\ -0.210 & -0.427 & 0.030 & -1.719 \\ -0.008 & -0.020 & 0.003 & -1.418 \\ -0.190 & -0.264 & -0.113 & -4.798\end{array}$

Correlation and $95 \% \mathrm{Cl}$

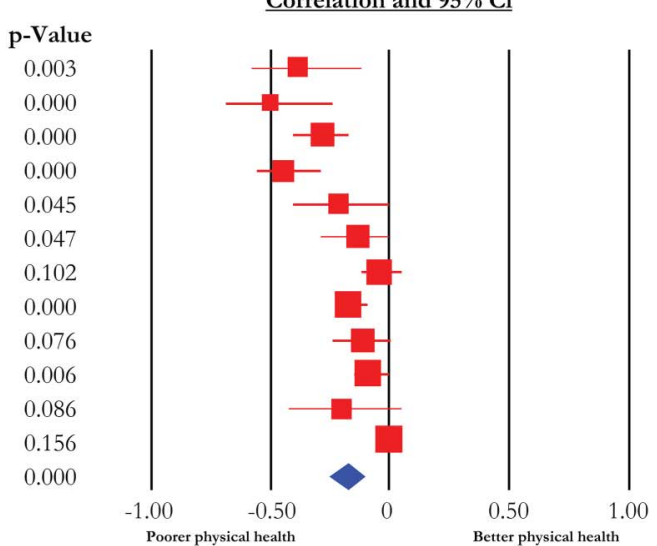

Figure 8 Stigma is associated with lower physical health (univariate results).

Univariate Results

Bozarth (1998)

Berger (2001)

Heckman (2002)

Prachakul (2007)

Wright (2007)

Sayles (2008)

Kalichman Cape Town (2009)

Kalichman Swaziland (2009)

Kalichman Atlanta (2009)

Li (2009)

Vyavaharkar (2012)

Rao (2012)

Clum (2009)

Dowshen (2009)

Newman (2012)

Dilorio (2009)

Summary Measure

Multivariate Results

Rueda (2012)

Mak (2007)

Summary measure
Statistics for Each Study

$\begin{array}{cccc}\text { Correlation } & \text { Lower limit } & \text { Upper limit } & \text { Z-Value } \\ -0.540 & -0.723 & -0.286 & -3.821 \\ -0.540 & -0.614 & -0.457 & -10.723 \\ -0.110 & -0.318 & 0.108 & -0.988 \\ -0.490 & -0.723 & -0.158 & -2.785 \\ -0.200 & -0.425 & 0.048 & -1.583 \\ -0.430 & -0.536 & -0.310 & -6.488 \\ -0.320 & -0.373 & -0.265 & -10.823 \\ -0.080 & -0.139 & -0.021 & -2.643 \\ -0.260 & -0.379 & -0.132 & -3.911 \\ -0.190 & -0.282 & -0.095 & -3.871 \\ -0.220 & -0.311 & -0.125 & -4.451 \\ -0.260 & -0.420 & -0.085 & -2.878 \\ -0.367 & -0.499 & -0.218 & -4.619 \\ -0.316 & -0.566 & -0.013 & -2.043 \\ -0.170 & -0.294 & -0.040 & -2.558 \\ -0.130 & -0.253 & -0.002 & -1.996 \\ -0.282 & -0.358 & -0.202 & -6.692\end{array}$

$-0.160$

$-0.420$

$-0.310$
-0.440
-0.616
-0.562

0.120
-0.224
-0.058
p-Value

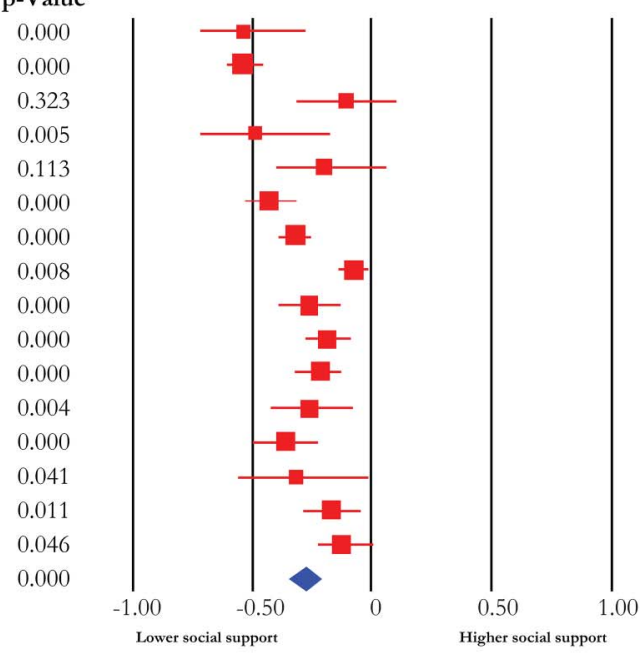

Point Estimate and $95 \% \mathrm{Cl}$

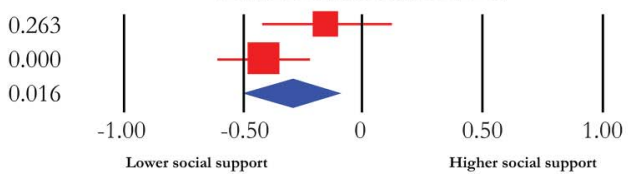

Figure 9 Stigma is associated with lower social support (univariate and multivariate results).

confounders found that people who experienced HIV-related stigma were $21 \%$ less likely to access or use health and social services. High heterogeneity was found in both univariate and multivariate analyses, respectively.

\section{Risk behaviour}

A statistically significant correlation between HIV-related stigma and unprotected sex was not found in univariate results (figure 12). There was no conclusive evidence of heterogeneity. One study that controlled for potential confounders did not find an association between HIV-related stigma and risk behaviour.

\section{Publication bias}

Publication bias was assessed for three meta-analyses with greater than 10 studies: depressive symptoms, physical health and social support (see online supplementary file 3 for funnel plots).

Mental health-depressive symptoms

Both funnel plot and 'trim-and-fill' analysis suggested that publication bias existed, and that people who experienced HIV-related stigma were at higher risk of depression.

\section{Physical health}

Despite publication bias, the key finding remains unchanged: people who experience HIV-related stigma were at higher risk of poorer physical health. Fail-safe N indicated that the association between HIV-related stigma and physical health likely existed. 
Univariate Results

Dilorio (2009)

Kenney (2008)

Sumari-de Boer (2012)

Nyamathi (2013)

Steward (2012)

Nachega (2004)

Summary measure

$\underline{\text { Multivariate results }}$

Peretti-Watel (2006)

Rintam aki (2006)

Reece (2001)

Nozaki (2011)

Earnshaw (2013)

Sayles (2009)

Carlucci (2008)

Summary measure
Statistics for Each Study

$\begin{array}{cccc}\text { Correlation } & \text { Lower limit } & \text { Upper limit } & \text { Z-Value } \\ -0.220 & -0.338 & -0.095 & -3.414 \\ -0.100 & -0.254 & 0.059 & -1.233 \\ -0.011 & -0.021 & -0.001 & -2.205 \\ -0.190 & -0.410 & 0.051 & -1.551 \\ 0.080 & 0.017 & 0.143 & 2.481 \\ -0.490 & -0.746 & -0.109 & -2.461 \\ -0.080 & -0.172 & 0.013 & -1.681\end{array}$

0.600

0.300

0.770

0.940

0.580

0.480

1.100

0.680

0.360
0.127
0.605
0.362
0.327
0.187
0.576
0.531

1.000
0.710
0.980
2.440
1.030
1.230
2.100
0.869

$-1.960$

$-2.739$

$-2.174$

$-0.127$

$-1.859$

$-1.529$

0.289

$-3.074$

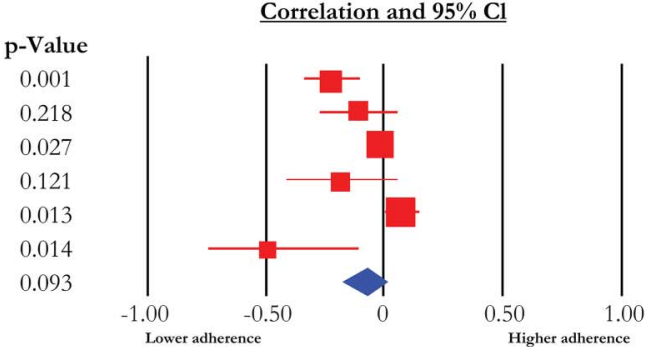

Odds Ratio and $95 \% \mathrm{Cl}$

0.050
0.006
0.034
0.899
0.063
0.126
0.773
0.002

0.002

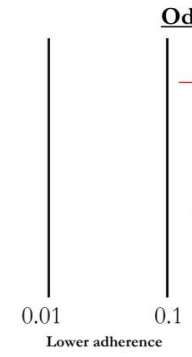

Figure 10 Stigma is associated with lower antiretroviral adherence (univariate and multivariate results).

Univariate Results
Heckman (2002)
Nyamathi (2013)
Dietz (2010)
Steward (2012)
Summary measure

$\underline{\text { Multivariate results }}$

Wingood (2007)

Reece (2001)

Naar-King (2007)

Kinsler (2007)

Wohl (2011)

Sayles (2009)

Abaynew (2011)

Brennan (2007)

Traeger (2011)

Summary measure

\begin{tabular}{cccc} 
& \multicolumn{3}{c}{ Statistics for Each Study } \\
Correlation & Lower limit & Upper limit & Z-Value \\
-0.420 & -0.583 & -0.225 & -4.004 \\
0.130 & -0.112 & 0.357 & 1.054 \\
0.000 & -0.003 & 0.003 & 0.000 \\
-0.090 & -0.152 & -0.027 & -2.793 \\
-0.083 & -0.199 & 0.035 & -1.385
\end{tabular}

p-Value
0.000
0.292
1.000
0.005
0.166

Correlation and $95 \% \mathrm{Cl}$

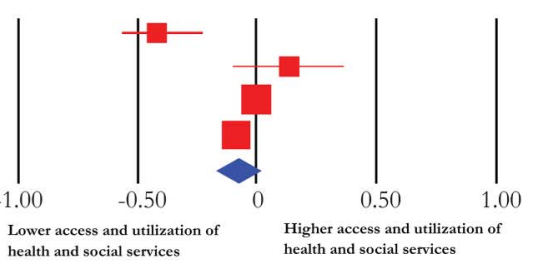

$\begin{array}{ll}0.400 & 0.191 \\ 0.780 & 0.615 \\ 0.970 & 0.733 \\ 0.350 & 0.130 \\ 0.900 & 0.810 \\ 0.230 & 0.100 \\ 0.320 & 0.113 \\ 0.980 & 0.960 \\ 0.740 & 0.453 \\ 0.792 & 0.675\end{array}$

$\begin{array}{ll}0.836 & -2.436 \\ 0.989 & -2.054 \\ 1.284 & -0.213 \\ 0.941 & -2.080 \\ 1.000 & -1.960 \\ 0.529 & -3.454 \\ 0.906 & -2.146 \\ 1.000 & -1.940 \\ 1.208 & -1.203 \\ 0.930 & 2.845\end{array}$

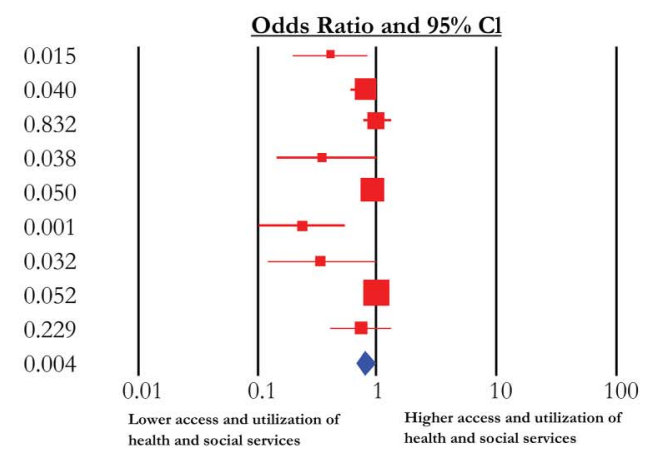

Figure 11 Stigma is associated with lower access and usage of health and social services (univariate and multivariate results).

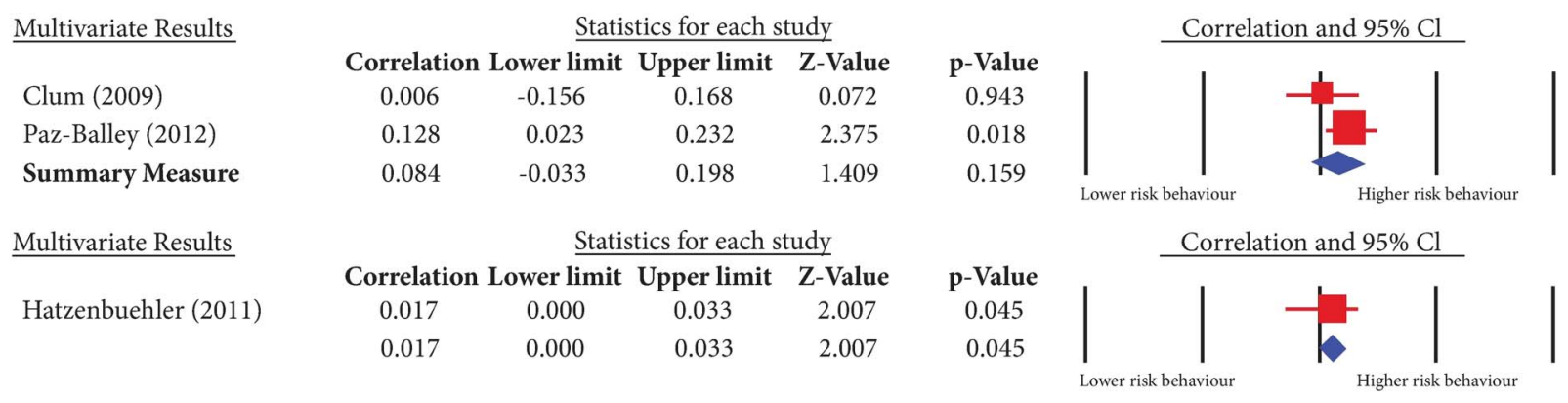

Figure 12 Stigma is associated with higher risk behaviour (univariate and multivariate results).

Social support

Despite publication bias, the main message remained unchanged: people who experienced HIV-related stigma were at greater risk of lower social support. Moreover, the fail-safe $\mathrm{N}$ suggested that the observed association was robust. 


\section{DISCUSSION}

\section{Summary of main findings}

This review examined the relationship between HIVrelated stigma and a variety of health and intermediate health-related outcomes by conducting a series of meta-analyses and pooling data from 64 studies of people living with HIV published after the advent of combination antiretroviral therapy. One key finding of this review is that experiencing HIV-related stigma is associated with higher levels of depression and lower levels of social support. Cross-sectional associations between HIV-related stigma and both depression and social support are reasonably well established given the large number of published studies included in this review and the corresponding strength of these associations. These findings are in agreement with those reported by a previous meta-analysis on the relationship between stigma, health and demographic factors in people living with HIV in North America. ${ }^{48}$ However, there are fewer studies examining the longitudinal associations between HIV-related stigma and depression or social support.

Some evidence suggests that various coping strategies have been shown to moderate the effect of HIV-related stigma on depression. For instance, disengagement coping (avoidant strategies including disengagement from the stressor, denial and/or wishful thinking) was found to moderate the relationship between stigma and depression, ${ }^{68}$ whereas mastery (a psychological resource related to personal control and self-efficacy) was found to be associated with lower levels of depression. ${ }^{69}$

There was also some evidence examining how the association between HIV-related stigma and depression may intersect with other forms of stigmatisation, such as homophobia, racism and gender discrimination. One recent study examining the role of stigma on MSM not only reported a strong correlation between HIV-related stigma and MSM-stigma, but also found an association between HIV-related stigma, sexual-stigma and depression. ${ }^{70}$ HIV-positive gay men reported considerable effects on mental health through increased levels of anxiety, depressive symptoms and avoidant-coping strategies. These men also experience higher levels of risk-taking behaviours ${ }^{71} 72$ and decreased uptake of HIV prevention and testing programmes. ${ }^{72}$ Among African, Caribbean and Black women in Canada, HIV-related stigma, depression, racism and gender discrimination were significantly correlated with each other, emphasising the importance of exploring the intersection of different types of stigmas. ${ }^{73}$

With respect to the relationship between HIV-related stigma and social support, previous research indicates that disclosure of one's HIV status to family, friends or healthcare professionals may be a stigmatising social process that can result in fear of rejection, ${ }^{28}$ or isolation and exclusion by support networks. ${ }^{78}$ Research examining social support as moderating the relationship between HIV-related stigma and depression, ${ }^{6}{ }^{74-76}$ points to the role of social support in buffering depression among people living with HIV. However, the extent to which people who experience a high degree of anticipated stigma may be less likely to disclose their HIV status for fear of social exclusion is unknown. ${ }^{7} 48$ Consequently, as questions surrounding the complex relationship between HIV-related stigma, depression and social support still remain, conducting longitudinal studies and exploring the role of potential moderating factors is warranted.

This review also found evidence suggesting the negative association between HIV-related stigma and intermediate health-related outcomes, including adherence to antiretroviral therapy, and access to and usage of health and social services. Although meta-analysis of univariate data for both adherence to antiretroviral therapy, and access to and usage of health and social services did not show a statistically significant correlation with HIV-related stigma, pooling data from studies that used multivariate models found significant associations. In support of our findings on the relationship between HIV-related stigma and adherence, a systematic review and meta-analyses specific to this topic similarly concluded that HIV-related stigma compromised the ability of people with HIV to adhere to antiretroviral therapy. ${ }^{77}$ Specifically, this review found that HIV-related stigma may compromise adherence by undermining social support and adaptive coping. ${ }^{77}$ Depression was also found to have a partial mediating effect on the negative association between HIV-related stigma and adherence. ${ }^{47}$ Additionally, stigma diminishes adherence through psychosocial processes, as people living with HIV who experience enacted and anticipated stigma may adopt strategies to conceal their status, leading to delayed treatment initiation or treatment interruptions. ${ }^{77} 78$ Despite a few studies that do not support the association between HIV-related stigma and access to and usage of health and social services, 7980 other studies support the notion that perceived stigma of people living with HIV was associated with low access to care, ${ }^{81}$ or delayed presentation in care, ${ }^{82}$ possibly stemming from perceived discrimination by healthcare providers. ${ }^{45} 83$

Some evidence to support the negative association between HIV-related stigma and both anxiety and health-related quality of life was found, but more research in these areas is necessary. While meta-analyses of univariate data between HIV-related stigma and anxiety showed a significant correlation, no significant associations were found when results of multivariate studies were pooled. Similarly, pooling univariate data for health-related quality of life showed a significant correlation with HIV-related stigma, while pooling data from multivariate studies failed to show a significant association. These findings may be explained by the observation that univariate data may be more comparable across studies-relative to multivariate data, which includes different sets of covariates. In addition, the low number of both univariate and multivariate studies included in these analyses suggest that the evidence on the cross-sectional associations 
between HIV-related stigma and both anxiety and quality of life are not well established, and highlights the need for more studies to elucidate these associations. It is important to note that one study with multivariate data that was excluded due to insufficient data required for meta-analysis found, however, that after adjusting for potential confounders, negative public attitudes toward HIV were associated with poorer quality of life and mental health problems. ${ }^{84}$

Multivariate data could not be pooled for the outcomes of physical health, emotional and mental distress and sexual risk behaviours. Pooled univariate findings limited the ability to draw more conclusive evidence between HIV-related stigma and these outcomes as these studies were not adjusted for potential confounders. Pooled univariate data for physical health was statistically significant, providing support for the negative association between HIV-related stigma and physical health. Of note, one study with multivariate data among HIV-positive women found that physical health variables (ie, viral load and CD4 counts) were not associated with HIV-related stigma. ${ }^{85}$ However, this study was not included for meta-analysis as it lacked sufficient information required for meta-analysis. Meta-analysis of univariate data for the relationship between HIV-related stigma and both emotional and mental distress and sexual risk behaviours showed non-significant associations, possibly due to the limited number of studies published to date with complete meta-analysable data. The dearth of literature in these areas suggest the need for additional studies examining these association, particularly those that control for potential confounders such as substance use, sexual orientation and health status.

Findings from this meta-analysis and our recent review of the qualitative evidence ${ }^{11}$ could be used to inform practitioners of the negative associations between HIV-related stigma and health-related outcomes, and they draw attention to the need to develop, test, implement and scale-up HIV stigma-reduction interventions. A recent systematic review of interventions to reduce the impact of HIV-related stigma found that while many individual-level and community-based interventions have been tested, only a handful of organisational interventions have been assessed for effectiveness. ${ }^{86}$ While there has been an increase in socioecological strategies to reduce stigma over the last decade ${ }^{86}$ there still remains a need for complex structural, and intersectional approaches to address the synergistic effects of multiple stigmatised identities. ${ }^{86-88}$ Finally, the few studies ${ }^{68} 697475$ available on moderating factors point to focusing on strategies that improve coping and strengthen social support networks among people living with HIV.

\section{Strengths and limitations}

The main strength of this systematic review and series of meta-analyses is that it examines a broad set of relationships between HIV-related stigma and health outcomes. It also performed a comprehensive search of the literature, used independent reviewers and a consensus approach to select and extract data from relevant papers, presented detailed information of included studies, performed a detailed quality appraisal of the included studies, used appropriate methods to combine the findings of studies and assessed the likelihood of publication bias where appropriate.

The most important limitation was the lack of a systematic evaluation of the mechanisms involved in the relationship between HIV-related stigma and health (mediation models), the role a variety of factors play in reducing the negative effects of HIV-related stigma on health (moderating models), and the intersection between HIV-related stigma and inter-related forms of social exclusion, as the stigma experienced by people living with HIV may be compounded by homophobia, racism, sexism and immigration status. ${ }^{10}$ These topics prevented a more nuanced evaluation of the complexity of HIV-related stigma, but they were outside the scope of the present review. These factors, however, are critical to the development of interventions, and they warrant focused reviews on their own merit. Other limitations included a search limited to papers published until September 2013, and the small number of studies that were pooled in meta-analyses for outcomes such as overall quality of life, anxiety, emotional and mental distress, adherence to antiretroviral therapy, access to and usage of health and social services and risk behaviours. Publication bias was not assessed for these outcomes as they included $<10$ studies. In addition, substantial heterogeneity was observed for depression, anxiety, physical health, social support and access to and usage of health and social services. Moreover, a lack of sensitivity, or subgroup analyses, taking into account the income levels of the countries where the primary studies took place, or based on the quality of the studies, may distort the applicability of this review's findings across different settings and jurisdictions, but this was also beyond the scope of this review.

In addition, while quality assessments revealed overall good quality in the domains of 'exposure' and 'outcome' for the included studies, low quality in the 'comparability' domain among individual studies was observed. This suggests that some studies controlled for at least one potential confounder, while the majority only presented bivariate associations. Consequently, this may have obscured the association between HIV stigma and health outcomes in this review. We followed the Preferred Reporting Items for Systematic Reviews and MetaAnalyses (PRISMA) recommendations and performed the identification, screening, selection and evaluation of papers in duplicate, but as with any systematic review, we cannot guarantee that we did not miss any papers.

\section{CONCLUSIONS}

This systematic review and series of meta-analyses support the notion that HIV-related stigma has a 
detrimental impact on a variety of health-related outcomes in people living with HIV. This body of work found significant associations between HIV-related stigma and depression, social support, adherence to antiretroviral therapy and access and usage of health and social services. Weaker relationships were observed between HIV-related stigma and anxiety, quality of life, physical health, emotional and mental distress and sexual risk practices. Few studies in these areas point to a greater need to conduct additional studies that explore HIV-related stigma as a predictor of healthrelated outcomes, and the potential moderating and mediating effects of other variables that may diminish these negative relationships. Future research should specifically focus on elucidating the mechanisms behind the detrimental relationship between HIV-related stigma and health outcomes to better inform multifaceted intersectoral interventions to reduce the impact of HIV-related stigma on the health and well-being of people living with HIV.

\section{Author affiliations}

${ }^{1}$ Institute for Mental Health Policy Research, Centre for Addiction and Mental Health, Toronto, Ontario, Canada

${ }^{2}$ Department of Psychiatry, University of Toronto, Toronto, Ontario, Canada

${ }^{3}$ Institute of Health Policy, Management and Evaluation, University of Toronto,

Toronto, Ontario, Canada

${ }^{4}$ Institute for Work and Health, Toronto, Ontario, Canada

${ }^{5}$ The Ontario HIV Treatment Network, Toronto, Ontario, Canada

${ }^{6}$ School of Social Work, McMaster University, Hamilton, Ontario, Canada

${ }^{7}$ Department of Clinical Epidemiology and Biostatistics, McMaster University, Hamilton, Ontario, Canada

${ }^{8}$ McMaster Health Forum, McMaster University, Hamilton, Ontario, Canada ${ }^{9}$ Factor-Inwentash Faculty of Social Work, University of Toronto, Toronto, Ontario, Canada

${ }^{10}$ Centre for Research on Inner City Health, Keenan Research Center, Li Ka Shing Knowledge Institute, St. Michael's Hospital, Toronto, Ontario, Canada

Contributors SR originated the project; designed and oversaw screening, data extraction, quality appraisal and synthesis, and was the principal writer. SM contributed substantially to data synthesis, interpretation of findings and writing the article. DG, JG, LC and SM contributed to screening, data synthesis and interpretation of the results. SC, QS and CL contributed to statistical analyses and interpretations of findings. MW and SBR contributed to the design of the study and provided critical revisions to the article for important intellectual content. All authors conceptualised ideas, interpreted findings, reviewed drafts of the article, and approved the final version.

Funding This work was supported by a Knowledge Synthesis grant from the Canadian Institutes of Health Research, and in-kind contributions provided by the Ontario HIV Treatment Network. The funders had no role in the study design, the data collection and analysis, the decision to publish, or in the preparation of the manuscript.

Competing interests None declared.

Provenance and peer review Not commissioned; externally peer reviewed.

Data sharing statement No additional data are available.

Open Access This is an Open Access article distributed in accordance with the Creative Commons Attribution Non Commercial (CC BY-NC 4.0) license, which permits others to distribute, remix, adapt, build upon this work noncommercially, and license their derivative works on different terms, provided the original work is properly cited and the use is non-commercial. See: http:// creativecommons.org/licenses/by-nc/4.0/

\section{REFERENCES}

1. Global Network of People Living with HIV (GNP+). The People Living with HIV Stigma Index. Secondary The People Living with HIV Stigma Index. 2015. http://www.stigmaindex.org/

2. Goffman E. Stigma: notes on the management of spoiled identity. Simon and Schuster, 2009.

3. Link BG, Phelan JC. Conceptualizing stigma. Annu Rev Sociol 2001;27:363-85.

4. Herek GM, Capitanio JP, Widaman KF. HIV-related stigma and knowledge in the United States: prevalence and trends, 1991-1999. Am J Public Health 2002;92:371-7.

5. Thomas BE, Rehman F, Suryanarayanan D, et al. How stigmatizing is stigma in the life of people living with HIV: a study on HIV positive individuals from Chennai, South India. AIDS Care 2005:17:795-801.

6. Heckman TG, Heckman BD, Kochman A, et al. Psychological symptoms among persons 50 years of age and older living with HIV disease. Aging Ment Health 2002;6:121-8.

7. Earnshaw VA, Chaudoir SR. From conceptualizing to measuring HIV stigma: a review of HIV stigma mechanism measures. AIDS Behav 2009;13:1160-77.

8. Herek GM, Capitanio JP. Public reactions to AIDS in the United States: a second decade of stigma. Am J Public Health 1993:83:574-7.

9. Bogart LM, Wagner GJ, Galvan FH, et al. Perceived discrimination and mental health symptoms among Black men with HIV. Cultur Divers Ethnic Minor Psychol 2011;17:295.

10. Earnshaw VA, Bogart LM, Dovidio JF, et al. Stigma and racial/ethnic HIV disparities: moving toward resilience. Am Psychol 2013;68:225-36.

11. Chambers L, Rueda S, Baker D, et al. Stigma, HIV and health: a qualitative synthesis. BMC Public Health 2015:15:1-17.

12. Elford J, Ibrahim F, Bukutu C, et al. HIV-related discrimination reported by people living with HIV in London, UK. AIDS Behav 2008;12:255-64.

13. Schuster MA, Collins R, Cunningham WE, et al. Perceived discrimination in clinical care in a nationally representative sample of HIV-infected adults receiving health care. J Gen Intern Med 2005;20:807-13.

14. Sears B. HIV discrimination in health care services in Los Angeles County: the results of three testing studies. Wash Lee J Civ Rts Soc Just 2008; 15:85

15. Heijnders M, Van Der Meij S. The fight against stigma: an overview of stigma-reduction strategies and interventions. Psychol Health Med 2006;11:353-63.

16. HIVIAIDS UNPo. Report on the Global AIDS Epidemic. Geneva: UNAIDS, 2006.

17. Brown L, Macintyre K, Trujillo L. Interventions to reduce HIV/AIDS stigma: what have we learned? AIDS Educ Prev 2003;15:49-69.

18. Weiss MG, Ramakrishna J, Somma D. Health-related stigma: rethinking concepts and interventions. Psychol Health Med 2006;11:277-87.

19. Jurgens R, Elliott R, Mensah M. Assessing the impact of law and policy on human rights and HIV prevention and care. XIV International AIDS Conference: Barcelona, Spain, 2002.

20. Hart TA, Blanco RM, Williams T. Research on HIV sexual risk behaviour among MSM from ethnoracial communities: a synthesis of the literature. In: Ontario gay men's HIV prevention strategy: gay, bi, MSM situation report. Toronto, ON: Ontario Ministry of Health and Long-Term Care, 2006.

21. Gee GC, Delva J, Takeuchi DT. Relationships between self-reported unfair treatment and prescription medication use, illicit drug use, and alcohol dependence among Filipino Americans. Am J Public Health 2007;97:933-40.

22. Yen IH, Ragland DR, Greiner BA, et al. Racial discrimination and alcohol-related behavior in urban transit operators: findings from the San Francisco Muni Health and Safety Study. Public Health Rep 1999; $114: 448-58$

23. Siegel K, Lekas HM, Schrimshaw EW. Serostatus disclosure to sexual partners by HIV-infected women before and after the advent of HAART. Women Health 2005;41:63-85.

24. Clark HJ, Lindner G, Armistead L, et al. Stigma, disclosure, and psychological functioning among HIV-infected and non-infected African-American women. Women Health 2004;38:57-71.

25. Kang E, Rapkin BD, Remien RH, et al. Multiple dimensions of HIV stigma and psychological distress among Asians and Pacific Islanders living with HIV illness. AIDS Behav 2005;9:145-54.

26. Heckman TG, Anderson ES, Sikkema KJ, et al. Emotional distress in nonmetropolitan persons living with HIV disease enrolled in a telephone-delivered, coping improvement group intervention. Health Psychol 2004;23:94-100. 
27. Black BP, Miles MS. Calculating the risks and benefits of disclosure in African American women who have HIV. J Obstet Gynecol Neonatal Nurs 2002;31:688-97.

28. Berger BE, Ferrans CE, Lashley FR. Measuring stigma in people with HIV: psychometric assessment of the HIV stigma scale. Res Nurs Health 2001;24:518-29.

29. Murphy DA, Austin EL, Greenwell L. Correlates of HIV-related stigma among HIV-positive mothers and their uninfected adolescent children. Women Health 2007;44:19-42.

30. Lee RS, Kochman A, Sikkema KJ. Internalized stigma among people living with HIV-AIDS. AIDS Behav 2002;6:309-19.

31. Kang E, Rapkin BD, DeAlmeida C. Are psychological consequences of stigma enduring or transitory? A longitudinal study of HIV stigma and distress among Asians and Pacific Islanders living with HIV illness. AIDS Patient Care STDs 2006;20:712-23.

32. Vanable PA, Carey MP, Blair DC, et al. Impact of HIV-related stigma on health behaviors and psychological adjustment among HIV-positive men and women. AIDS Behav 2006;10:473-82.

33. Vance DE. Self-rated emotional health in adults with and without HIV 1. Psychol Rep 2006;98:106-8.

34. Gonzalez A, Solomon SE, Zvolensky MJ, et al. The interaction of mindful-based attention and awareness and disengagement coping with HIV/AIDS-related stigma in regard to concurrent anxiety and depressive symptoms among adults with HIV/AIDS. J Health Psychol 2009;14:403-13.

35. Ivanova EL, Hart TA, Wagner AC, et al. Correlates of anxiety in women living with HIV of reproductive age. AIDS Behav 2012;16:2181-91.

36. Bogart LM, Wagner GJ, Galvan FH, et al. Longitudinal relationships between antiretroviral treatment adherence and discrimination due to HIV-serostatus, race, and sexual orientation among African-American men with HIV. Ann Behav Med 2010;40:184-90.

37. Capron DW, Gonzalez A, Parent J, et al. Suicidality and anxiety sensitivity in adults with HIV. AIDS Patient Care STDS 2012;26:298-303.

38. Carrico AW. Elevated suicide rate among HIV-positive persons despite benefits of antiretroviral therapy: implications for a stress and coping model of suicide. Am J Psychiatry 2010;167:117-9.

39. Greeff M, Uys LR, Wantland D, et al. Perceived HIV stigma and life satisfaction among persons living with HIV infection in five African countries: a longitudinal study. Int J Nurs Stud 2010;47:475-86.

40. Vyavaharkar M, Moneyham L, Murdaugh C, et al. Factors associated with quality of life among rural women with HIV disease. AIDS Behav 2012;16:295-303.

41. Holzemer WL, Human S, Arudo J, et al. Exploring HIV stigma and quality of life for persons living with HIV infection. $J$ Assoc Nurses AIDS Care 2009;20:161-8.

42. Fife BL, Wright ER. The dimensionality of stigma: a comparison of its impact on the self of persons with HIV/AIDS and cancer. $J$ Health Soc Behav 2000;41:50-67.

43. Sandelowski M, Lambe C, Barroso J. Stigma in HIV-positive women J Nurs Scholarsh 2004;36:122-8.

44. Dlamini PS, Wantland D, Makoae LN, et al. HIV stigma and missed medications in HIV-positive people in five African countries. AIDS Patient Care STDS 2009;23:377-87.

45. Kinsler JJ, Wong MD, Sayles JN, et al. The effect of perceived stigma from a health care provider on access to care among a low-income HIV-positive population. AIDS Patient Care STDS 2007;21:584-92.

46. Golin C, Isasi F, Bontempi JB, et al. Secret pills: HIV-positive patients' experiences taking antiretroviral therapy in North Carolina. AIDS Educ Prev 2002;14:318-29.

47. Rao D, Feldman BJ, Fredericksen RJ, et al. A structural equation model of HIV-related stigma, depressive symptoms, and medication adherence. AIDS Behav 2012;16:711-6.

48. Logie C, Gadalla TM. Meta-analysis of health and demographic correlates of stigma towards people living with HIV. AIDS Care 2009;21:742-53.

49. Leaver CA, Bargh G, Dunn JR, et al. The effects of housing status on health-related outcomes in people living with HIV: a systematic review of the literature. AIDS Behav 2007;11:85-100.

50. Wells G, Shea B, O'connell D, et al. The Newcastle-Ottawa Scale (NOS) for assessing the quality of nonrandomised studies in meta-analyses. 2000.

51. Borenstein M, Hedges L, Higgins J, et al. Introduction to meta-analysis: John Wiley \& Sons, 2011.

52. Duval SJ. The trim and fill method. In: Rothstein HR, Sutton AJ, Borenstein M. Eds. Publication bias in meta-analysis: prevention, assessment, and adjustments. Chichester,UK: Wiley, 2005:127-44.

53. Borenstein MH, LV; Higgins JPT; Rothstein HR. Introduction to meta-analysis. West Sussex, UK: John Wiley \& Sons, 2009.
54. Sowell RL, Lowenstein A, Moneyham L, et al. Resources, stigma, and patterns of disclosure in rural women with HIV infection. Public Health Nurs 1997;14:302-12.

55. Kalichman SC, Simbayi LC, Cloete A, et al. Measuring AIDS stigmas in people living with HIV/AIDS: the Internalized AIDS-Related Stigma Scale. AIDS Care 2009;21:87-93.

56. Radloff LS. The CES-D scale a self-report depression scale for research in the general population. Appl Psychol Meas 1977;1:385-401.

57. Derogatis LR, Spencer P. Brief symptom inventory: BSI. Upper Saddle River, NJ: Pearson, 1993.

58. Ware Jr JE, Kosinski M, Keller SD. A 12-Item Short-Form Health Survey: construction of scales and preliminary tests of reliability and validity. Med Care 1996;34:220-33.

59. Marteau TM, Bekker $\mathrm{H}$. The development of a six-item short-form of the state scale of the Spielberger State-Trait Anxiety Inventory (STAI). Br J Clin Psychol 1992;31(Pt 3):301-6.

60. Derogatis LR, Unger R. Symptom Checklist-90-Revised. Corsini encyclopedia of psychology. 2010, pp 1-2.

61. WHO. WHOQOL-HIV BREF. http://www.who.int/mental health/ evidence/WHOQOL-HIV BREF.pdf. Secondary WHOQOL-HIV BREF. http://www.who.int/mental_health/evidence/WHOQOL-HIV BREF.pdf

62. Holmes WC, Shea JA. A new HIV/AIDS-targeted quality of life (HAT-QoL) instrument: development, reliability, and validity. Med Care 1998;36:138-54.

63. Wu AW, Hays RD, Kelly S, et al. Applications of the medical outcomes study health-related quality of life measures in HIV/AIDS. Qual Life Res 1997:6:531-54.

64. Brock DM, Sarason IG, Sarason BR, et al. Simultaneous assessment of perceived global and relationship-specific support. J Soc Pers Relationships 1996;13:143-52.

65. Sherbourne CD, Stewart AL. The MOS social support survey. Soc Sci Med 1991;32:705-14.

66. Chesney M, Ickovics J, Chambers D, et al. Patient Care Committee \& Adherence Working Group of the Outcomes Committee of the Adult AIDS Clinical Trials Group (AACTG). Self-reported adherence to antiretroviral medications among participants in HIV clinical trials: the AACTG adherence instruments. AIDS Care 2000;12:255-66.

67. Group NIoMHMHPT. Demographic and behavioral predictors of sexual risk in a multisite HIV prevention trial. AIDS 1997;112):S21-7.

68. Varni SE, Miller CT, McCuin T, et al. Disengagement and engagement coping with HIV/AIDS stigma and psychological well-being of people with HIV/AIDS. J Soc Clin Psychol 2012;31:123-50.

69. Rueda S, Gibson K, Rourke SB, et al. Mastery moderates the negative effect of stigma on depressive symptoms in people living with HIV. AIDS Behav 2012;16:690-9.

70. Wohl AR, Galvan FH, Carlos JA, et al. A comparison of MSM stigma, HIV stigma and depression in HIV-positive Latino and African American men who have sex with men (MSM). AIDS Behav 2013;17:1454-64

71. Hatzenbuehler ML, O'Cleirigh C, Mayer $\mathrm{KH}$, et al. Prospective associations between HIV-related stigma, transmission risk behaviors, and adverse mental health outcomes in men who have sex with men. Ann Behav Med 2011:42:227-34

72. Smit PJ, Brady M, Carter M, et al. HIV-related stigma within communities of gay men: a literature review. AIDS Care 2012;24:405-12.

73. Logie C, James L, Tharao W, et al. Associations between HIV-related stigma, racial discrimination, gender discrimination, and depression among HIV-positive African, Caribbean, and Black women in Ontario, Canada. AIDS Patient Care STDS 2013;27:114-22.

74. Li L, Lee SJ, Thammawijaya P, et al. Stigma, social support, and depression among people living with HIV in Thailand. AIDS care 2009:21:1007-13

75. Prachakul W, Grant JS, Keltner NL. Relationships among functional social support, HIV-related stigma, social problem solving, and depressive symptoms in people living with HIV: a pilot study. $J$ Assoc Nurses AIDS Care 2007;18:67-76.

76. Rao D, Chen WT, Pearson CR, et al. Social support mediates the relationship between HIV stigma and depression/quality of life among people living with HIV in Beijing, China. Int J STD AIDS 2012;23:481-4.

77. Katz IT, Ryu AE, Onuegbu AG, et al. Impact of HIV-related stigma on treatment adherence: systematic review and meta-synthesis. J Int AIDS Soc 2013;16(Suppl 2):18640.

78. Rintamaki LS, Davis TC, Skripkauskas S, et al. Social stigma concerns and HIV medication adherence. AIDS Patient Care STDS 2006;20:359-68. 
79. Naar-King S, Bradford J, Coleman S, et al. Retention in care of persons newly diagnosed with HIV: outcomes of the Outreach Initiative. AIDS Patient Care STDs 2007;21(Suppl 1): S40-8.

80. Dietz E, Clum GA, Chung SE, et al. Adherence to scheduled appointments among HIV-infected female youth in five US cities. $J$ Adolesc Health 2010;46:278-83.

81. Steward WT, Bharat S, Ramakrishna J, et al. Stigma is associated with delays in seeking care among HIV-infected people in India. $J$ Int Assoc Provid AIDS Care 2013;12:103-9.

82. Abaynew $\mathrm{Y}$, Deribew A, Deribe K. Factors associated with late presentation to HIV/AIDS care in South Wollo ZoneEthiopia: a case-control study. AIDS Res Ther 2011;8:8.

83. Nyamathi A, Ekstrand M, Zolt-Gilburne J, et al. Correlates of stigma among rural Indian women living with HIV/AIDS. AIDS Behav 2013;17:329-39.
84. Rongkavilit C, Wright $\mathrm{K}$, Chen $\mathrm{X}$, et al. HIV stigma, disclosure and psychosocial distress among Thai youth living with HIV. Int J STD AIDS 2010;21:126-32.

85. Wagner AC, Hart TA, Mohammed S, et al. Correlates of HIV stigma in HIV-positive women. Arch Womens Ment Health 2010;13:207-14.

86. Stangl AL, Lloyd JK, Brady LM, et al. A systematic review of interventions to reduce HIV-related stigma and discrimination from 2002 to 2013: how far have we come? J Int AIDS Soc 2013;16 (Suppl 2):18734.

87. Reis RK, Galvão MT, Gir E. Challenges to an effective response for addressing stigma and discrimination related to HIV: from denial of rights to construction of support networks. J Int AIDS Soc 2013:16:18931.

88. Sengupta S, Banks B, Jonas D, et al. HIV interventions to reduce HIV/AIDS stigma: a systematic review. AIDS Behav 2011;15:1075-87. 